\title{
Transfer of training as a function of intra-list response similarity and degree of original list learning 1
}

\section{J. HOMZIE, University of Virginia, Charlottesville, Va. 22901, JON WEIMER, JEFFREY SCHWARTZ, and WILLIAM WATERS, University of Denver, Denver, Colo. 80210}

To investigate the effects of degree of original list leaming (DOL) and intralist response similarity (IRS) on transfer phenomena, 260 Ss were assigned to learn, by the study-test trial procedure, one of five transfer paradigms. The main transfer results were: (a) paradigm $C-B>C-A=A-B r>$ $B r-A$; and (b) an IRS by DOL interaction.

The two-phase conception of paired-associate learning leads to the implication that when transfer-list response terms are presented in the initial list (e.g., $A-B, C \cdot B$ and $A \cdot B, A-B r$ paradigms), increasing the degree of original list learning (DOL) should have two effects: (a) facilitation due to increased response availability and differentiation, and (b) interference from inappropriate first-list associations (cf. Martin, 1965). Increasing the degree of intralist response similarity (IRS) should place more weight on the first of these two factors such that greater DOL should have a relatively facilitating effect. At low intralist response similarity (LIRS), increased first-list learning should have less of a "facilitating effect." If the transfer-list response terms are presented as first-list stimuli (e.g., A-B, C-A and A-B, Br-A paradigms), $S$ need not integrate these units in order to master the initial task. In this case, there would be less familiarization with the units; consequently, the IRS by DOL interaction would not be as potent, i.e., a Paradigm by IRS by DOL interaction would be expected.

\section{METHOD}

The Ss were 260 University of Denver undergraduates. The 2 by 2 by 5 factorial design included two levels of IRS (high vs low), two levels of DOL (3/6 correct vs $6 / 6$ correct plus one additional study trial), and five transfer paradigms: (a) A-B, C-B ; (b) A-B, C-A ; (c) A-B, A-Br; (d) A-B, Br-A; and (e) A-B, C-D. Table 1 shows the verbal materials which comprised the various paradigms. The CVCs were selected in such a manner that the high-IRS (HIRS) transfer-task response terms utilized only three consonants, each being used four times, whereas 12 different consonants were used once each to form the LIRS terms. By reading across Table 1, it is possible to determine which units were paired. For example, in the A-B, C-A condition (HIRS), "ZYX" was paired with "HEAVEN" for the first task, and "INSANE-ZYX" formed the second (transfer) task.

Each pair was presented on a Stowe memory drum for $2 \mathrm{sec}$ on study trials, and Ss were allowed $2 \mathrm{sec}$ to respond to the stimulus member on the test trials. There were four different orders of each list.

After two Ss had been randomly assigned to each of the experimental paradigms (i.e., $\mathrm{C}-\mathrm{A}, \mathrm{C}-\mathrm{B}, \mathrm{A} \cdot \mathrm{Br}$, and $\mathrm{Br}-\mathrm{A}$ ) for any particular DOL and IRS treatment combination, then two Ss were placed into the appropriate control condition (C-D) and received the same number of trials on their first list as the average number of trials the above mentioned Ss had spent in learning their respective initial tasks. In that $S s$ under the various conditions of similarity and DOL would not be expected to reach their initialtask learning criterion in the same number of training trials, this procedure provided separate control groups for each of the four IRS and DOL treatment combinations. Control groups with practice on a similar class of verbal material as difficult to learn and containing the same similarity relations as the experiment treatments would have been preferable; however, such a procedure is difficult to implement.

\section{RESULTS}

A 2 by 2 by 4 (control groups omitted) factorial analysis of variance was performed on the number of trials it took each $S$ to reach his particular first-list acquisition criterion. This analysis resulted in significance at the .01 level for: (a) main effect of paradigms $[F(3,192)=17.9]$; (b) main effect of IRS $[F(1,192)=99.8]$; (c) main effect of DOL $[F(1,192)=81.5]$; (d) a Paradigm by IRS interaction $[F(3,192)=8.5]$; (e) a Paradigm by DOL interaction $[F(1,192)=4.7] ;(f)$ an IRS by DOL interaction $[F(1,192)=15.7]$; and (g) a Paradigm by IRS by DOL interaction $[F(3,192)=3.7]$. As can be seen in Fig. 1, it took more trials to master the HIRS material and to attain the $6 / 6+1$ acquisition criterion. Performance was statistically superior $[t(206)=7.2, p<.01]$ for Paradigms $\mathrm{C}-\mathrm{A}$ and $\mathrm{Br}-\mathrm{A}$ than for Paradigms C.B and A-Br. The interactions resulted from IRS and DOL being more potent parameters for the $\mathrm{C}-\mathrm{B}$ and $\mathrm{A}-\mathrm{Br}$ conditions.

A 2 by 2 by 4 (without the control groups) analysis of variance was performed on the total number of correct responses given by each $S$ during the 10 test trials on the transfer task. The analysis resulted in statistical significance at the .01 level for: (a) main effect of paradigms $[F(3$, $192)=15.6]$; (b) main effect of IRS $[F(1,192)=42.8]$; (c) main effect of DOL $[F(1,192)=12.9]$; and (d) the IRS by DOL interaction $[F(1,192)=5.1]$. The $F$ ratios did not change significantly when the four control groups were included in the analysis; therefore, these results are not reported.

Collapsing over DOL and IRS, Ss in the C-B, C-A, A-Br, C-D, and Br-A paradigms averaged $29.8,22.0,20.8,19.1$, and 16.4

Table 1

Verbal Materials Which Comprised the Various Paradigms

\begin{tabular}{|c|c|c|c|c|c|c|c|c|c|c|c|}
\hline \multicolumn{2}{|c|}{$\mathrm{C}-\mathrm{B}$} & \multicolumn{2}{|c|}{$A-B r$} & \multicolumn{2}{|c|}{$\mathbf{C}-\mathbf{A}$} & \multicolumn{2}{|c|}{$\mathbf{B r}-\mathbf{A}$} & \multicolumn{2}{|l|}{ C-D } & \multicolumn{2}{|c|}{ Transfer Task } \\
\hline \multicolumn{12}{|c|}{ LIRS } \\
\hline Heaven & DAQ & Insane & WUT & DAQ & Heaven & WUT & Insane & Heaven & $?$ & Insane & DAQ \\
\hline Insect & CEF & Roving & $Z Y X$ & CEF & Insect & ZYX & Roving & Insect & \# & Roving & CEF \\
\hline Wagon & KIG & Tranquil & CEF & KIG & Wagon & CEF & Tranquil & Wagon & 8 & Tranquil & KIG \\
\hline Office & ZYX & Little & NOJ & ZYX & Office & NOJ & Little & Office & 5 & Little & $Z Y X$ \\
\hline Army & NOJ & Adept & KIG & NOJ & Army & KIG & Adept & Army & $\$$ & Adept & NOJ \\
\hline Kitchen & WUT & Empty & DAQ & WUT & Kitchen & $\mathrm{DAQ}$ & Empty & Kitchen & 3 & Empty & WUT \\
\hline \multicolumn{12}{|c|}{ HIRS } \\
\hline Heaven & $Z Y X$ & Insane & QOX & ZYX & Heaven & QOX & Insane & Heaven & $?$ & Insane & ZYX \\
\hline Insect & ZEQ & Roving & QUZ & ZEQ & Insect & QUZ & Roving & Insect & \# & Roving & $Z E Q$ \\
\hline Wagon & XIQ & Tranquil & $\mathbf{Z Y X}$ & XIQ & Wagon & $Z Y X$ & Tranquil & Wagon & 8 & Tranquil & XIQ \\
\hline Office & $\mathrm{XAZ}$ & Little & ZEQ & XAZ & Office & $\mathrm{ZEQ}$ & Little & Office & 5 & Little & XAZ \\
\hline Army & QUZ & Adept & XIQ & QUZ & Army & XIQ & Adept & Army & $\$$ & Adept & QUZ \\
\hline Kitchen & QOX & Empty & XAZ & QOX & Kitchen & XAZ & Empty & Kitchen & 3 & Empty & QOX \\
\hline
\end{tabular}



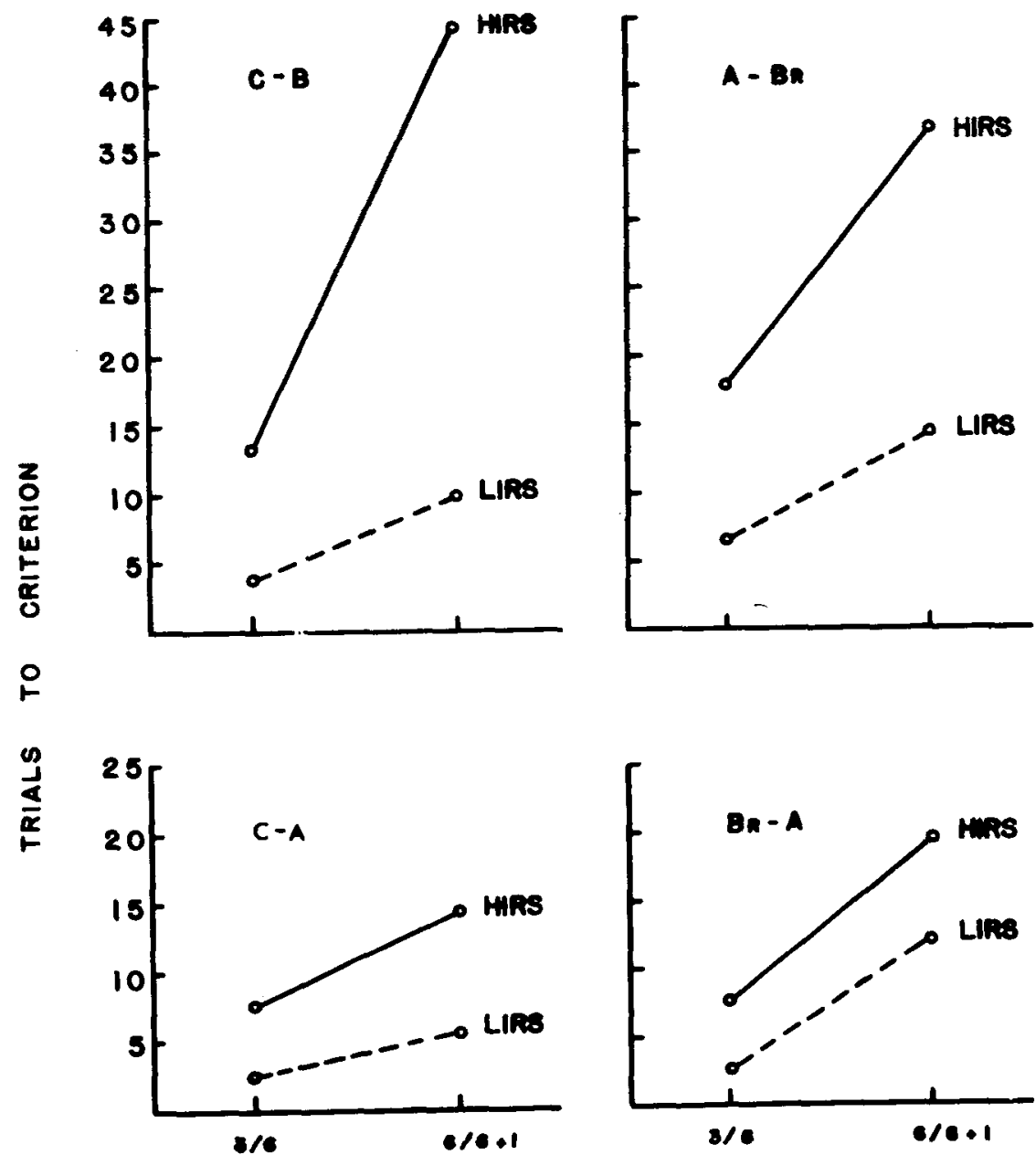

Fig. 1. The mean number of trials to the particular first-list acquisition criterion for the various paradigms and similarity conditions.

CVCs served as the response terms (i.e., C-B, $\mathrm{A}-\mathrm{Br}$ ). This finding is in agreement with previous studies which have found response meaningfulness to be a more potent factor than stimulus meaningfulness (e.g., Cieutat, Stockwell, \& Noble, 1958). The Paradigm by IRS interaction indicates that the superiority of the $\mathrm{C}-\mathrm{A}$ and $\mathrm{Br}-\mathrm{A}$ paradigms resulted mainly from the relatively better performance of these two groups at HIRS (see Fig. 1). One interpretation of this interaction is that high intralist similarity on the response side interfered with both the response-learning and associative-learning stages, whereas high intralist similarity on the stimulus side merely hindered the associative stage. Another possible explanation is that $\mathrm{C}$-A and $\mathrm{Br}-\mathrm{A}$ Ss engaged in stimulus selection such that their HIRS stimulus units were effectively of low similarity.

\section{Transfer Task}

In agreement with the two-pháse conception, those Ss which had previously learned the second-list responses as. initial-list response terms (i.e., C-B and A-Br paradigms) exhibited superior performance to Ss which had initially learned these units as stimulus items (i.e., C-A and Br-A groups). In addition, the $\mathrm{Br}-\mathrm{A}$ and $\mathrm{A}-\mathrm{Br}$ paradigms, which permitted relatively poorer list discrimination and contained greater sources of inapprópriate first-list associations, were statistically inferior to the

\section{DECREE OF FIRST - LIST LEARNING}

total correct responses, respectively, for the 10 transfer test trials. The only paradigm that was significantly different from the control (i.e., C-D) was the C-B condition $[t(102)=5.4, p<.01]$. Multiple $t$ tests indicated that all experimental paradigms were statistically different from each other in overall performance $(p<.01)$ except for the C-A, A-Br comparison, which was nonsignificant. Of interest was the fact that the paradigms in which the transfer-list response terms served as response terms for the first list (i.e., C-B and $\mathrm{A}-\mathrm{Br}$ ) exhibited statistically superior performance $[t(206)=4.4, p<.01]$ to the transfer paradigms in which these units served as stimuli for the initial list (i.e., C-A and Br-A).

Figure 2 depicts the main effects of IRS, DOL, and their interaction. As can be seen, lower intralist response similarity and greater degree of original list learning both lead to better performance. However, DOL is a much more potent factor for HIRS than for LIRS. This interpretation of the DOL by IRS interaction is supported statistically in that, for HIRS, the performance of Ss trained to the $6 / 6+1$ criterion is superior to that of Ss trained to the $3 / 6$ criterion $[t(102)=4.2, p<.01]$, whereas for LIRS, this comparison is not statistically significant $[\mathrm{t}(102)=0.9]$. The HIRS Ss trained to the $6 / 6+1$ criterion exhibited better performance than their comparable control group $[t(63)=2.75, p<.01]$. No other IRS by DOL treatment combination performed statistically better than its control group.

\section{DISCUSSION \\ First List}

In agreement with previous studies (e.g., Newman \& Buckhout, 1962), intralist stimulus similarity (cf. Paradigms C-A and $\mathrm{Br}-\mathrm{A}$ ) and intralist response similarity (cf. Paradigms C-B and A-Br) were inversely related to acquisition performance. The results also indicated that those paradigms containing high meaningful words as response terms (i.e., C-A, Br-A) were learned quicker than those paradigms which reversed the units such that low meaningful

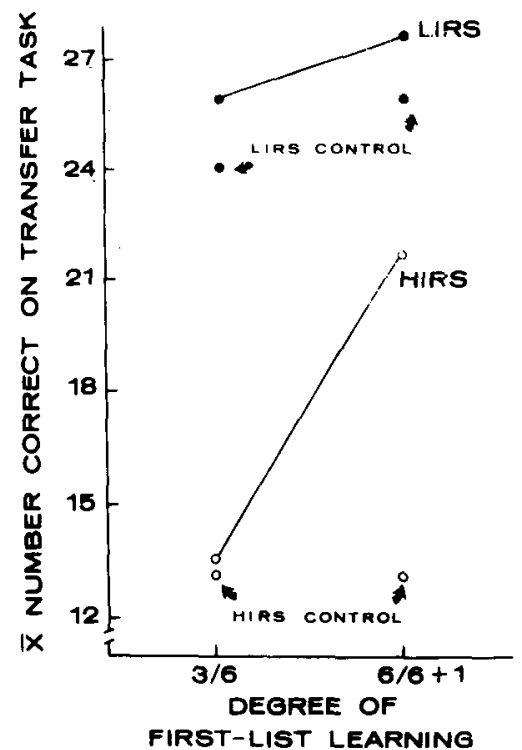

Fig. 2. Mean number of correct responses on the $\mathbf{1 0}$ transfer test trials as a function of DOL and level of IRS. 
C-B and C-A groups $[t(206)=5.2, p<.01]$. The relative ordering of the groups is in agreement with expectations from the two-phase conception (cf. Martin, 1965).

The results indicate that at LIRS there is no effect of DOL on transfer performance. Two previous experiments that involved comparable C-B and A-Br paradigms (Jung, 1962; Postman, 1962) minimized intralist response similarity and have also failed to report a significant DOL transfer effect. $A$ third study that included the C-A and $\mathrm{A}-\mathrm{Br}$ paradigms (Schulman, 1967) used high-frequency nouns as response terms, a list which presumably would constitute LIRS items, and found no DOL effect. Dean \& Kausler (1964) minimized IRS and reported poorer transfer performance with increased DOL for the C-B paradigm. It is interesting to note that the present study, Postman (1962), and Jung (1962), each of which contained comparable C-B paradigms, utilized words as stimuli for the transfer task, whereas Dean \& Kausler (1964) used nonsense syllables. Dean \& Kausler (1964) suggest the possibility that backward associations from first-list learning increase more with greater DOL when nonsense syllables serve as stimuli than when words serve as stimulus terms. Except for the Dean \& Kausler (1964) study, the literature is consistent in reporting no transfer effect of DOL with transfer-task response terms of low intralist similarity.

Turning to HIRS, with increased DOL, highly similar response units would be expected to lead to relatively better transfer performance than LIRS units because of the greater importance of response differentiation. Figure 2 shows that the expected DOL by IRS interaction was obtained. However, it would seem that Ss serving in the $C-A$ and $B r-A$ paradigms would have had less opportunity to become familiar with the terms during first-list learning that were to later become transfer-task responses. For this reason, the IRS by DOL interaction was expected not to be as potent for these Ss. The subsequent response terms were on the stimulus side during first-list learning for these paradigms, and consequently, $S$ could have engaged in stimulus selection or, at the very least, did not need to learn these units as well as they would have needed to if they had been initial-task response terms. In addition, it took less trials for Ss in Paradigms C-A and $\mathrm{Br}-\mathrm{A}$ to attain the first-list acquisition criterion, affording these $S$ s even less opportunity for familiarization with the critical items. A possible explanation of the failure to find a Paradigm by IRS by DOL interaction is that the similar units were, indeed, so similar that even when they were placed on the stimulus side $S$ needed to learn to clearly distinguish between these verbal units in order to reach the $6 / 6+1$ acquisition criterion. Subsequently, on the second task, where Ss had to transfer stimulus differentiation to response learning and to response differentiation, prior exposure to the highly similar material at the severe acquisition criterion led to as much relative facilitation in performance as the conditions in which the critical items had been response terms.

When number of trials spent on first-list learning was covaried, there were no changes in the results of the transfer-task analyses. In addition, the C-D control groups (see Fig. 2) did not show differential transfer performance as a function of degree of first-list learning. These results suggest that, within the limits of training manipulated in the present study, there was no differential effect of learning-to-learn and warm-up. The control groups, however, are probäbly inappropriate. They differ in meaningfulness from that used in the experimental paradigms, and in addition, they failed to control for the similarity conditions. As a further note of caution, during first-list training, similarity was manipulated on the stimulus side for Paradigms $\mathrm{C} \cdot \mathrm{A}$ and $\mathrm{Br}-\mathrm{A}$. Thus, initial task IRS and intralist stimulus similarity, as well as stimulus vs response-term meaningfulness were varied in the comparison of the $C-B$ and $\mathrm{A}-\mathrm{Br}$ paradigms with Paradigms $\mathrm{C}-\mathrm{A}$ and
Br-A. Paradigms, however, did not interact as a variable in the transfer results, indicating that the IRS by DOL interaction held for all groups.

\section{REFERENCES}

CIEUTAT, V. J., STOCKWELL, F. E., \& NOBLE C. E. The interaction of ability and amount of practice with stimulus and response meaningfulness (m, $\left.\mathrm{m}^{3}\right)$ in paired-associate learning. Journal of Experimental Psychology, 1958, 56, 193-202.

DEAN, M. G., \& KAUSLER, D. H. Degree of first-list learning and stimulus meaningfulness as related to transfer in the $A \cdot B, C-B$ paradigm. Journal of Verbal Learning \& Verbal Behavior, $1964,3,330-334$.

JUNG, J. Training a function of degree of first-list leaming. Joumal of Verbal Learning \& Verbal Behavior, 1962, 1, 197-199.

MARTIN, E. A. Transfer of verbal paired-associates. Psychological Review, 1965 72, 327-343.

NEWMAN, S. E., \& BUCKHOUT, R. S-R and R-S learning as functions of intra-list similarity. American Joumal of Psychology, 1962, 75, 429-436.

POSTMAN, $L$. Transfer of training as a function of experimental paradigm and degree of first-list learning. Journal of Verbal Learning \& Verbal Behavior, 1962, 1, 109-118.

SCHULMAN, R. M. Paired-associate transfer following early stages of list 1 leaming. Journal of Experimental Psychology, 1967, 73, 589-594.

NOTE

1. This investigation was supported by Public Health Service Research Grant MH 14017.

\section{On the relative usefulness of monaural and binaural cues in locating sound in space}

\section{ROBERT A. BUTLER, University of Chicago, Chicago, Ill. 60637}

The cues for locating sound in the vertical plane are predominantly monaural; binaural cues are available for horizontal plane localization. Ss, required to locate repetitive noise bursts originating in the vertical plane, performed significantly above chance level $(p<.005)$. Performance in locating sound sources in the horizontal was significantly superior to that recorded for the vertical plane $(p<.005)$. These results support the claims that relatively accurate sound localization can take place when only monaural cues are available. But the significant contribution of binaural cues is clearly evident if the angle between sound sources is made small.
Lately, there has been a flurry of interest in the ability of man to locate sound solely on the basis of monaural cues (Batteau, 1968; Bauer et al, 1966; Butler \& Naunton, 1967; Fisher \& Freedman, 1968a, b; Perrott \& Elfner, 1968). The way these experiments are usually run is that the listener is asked to locate sounds with and without one ear being blocked. And, indeed, when the angle between loudspeakers is reasonably large, Ss can locate as accurately listening with one as they can with two ears (Fisher \& Freedman, 1968a). This is interesting. Apparently, spectral cues serve well the listener when he is forced to rely on one ear. There may be still other cues operating. Batteau (1968) believed that the contours of the pinna transformed the sound into a configuration of repetitive wavefronts. He was able to demonstrate, on an enlarged model of the pinna, that the temporal intervals between 